incidence after induced abortion reported by Panayoti et al. ${ }^{16}$ Possibly the slightly raised rate in the present study might be related to the contraceptive method used after termination and before subsequent conception. ${ }^{1.5}$ Of particular importance is the number of spontaneous second-trimester abortions. Cervical incompetence resulting from induced abortion by vaginal aspiration has been a cause for concern. ${ }^{11} 12 \mathrm{~A}$ recent investigation has shown that cervical dilatation beyond $12 \mathrm{~mm}$ at termination by vaginal aspiration is associated with enlarged cervical canal diameters and possible loss of cervical integrity. ${ }^{17}$ Similar concern for cervical incompetence after prostaglandininduced abortion has been expressed, and routine prophylactic suturing of the cervix is advocated in such cases. ${ }^{\text {" }}$ Our evidence suggests that such radical management is not justified. In the present series only one abortion in the index group may have been due to cervical incompetence, possibly resulting from an initial termination by vaginal aspiration at 14 weeks' gestation. More sinister, and probably important, however, is the occurrence of cervicovaginal fistulae after prostaglandin-induced abortion..$^{19}$ The precise aetiology of these lesions is at present obscure" "; the prostaglandin used for the abortion has been implicated, but this theory has been recently dismissed." 1

None of our patients reported subfertility, and none was found in a survey assessing delayed morbidity ; we acknowledge, however, that we have only been able to study the fertility of a limited percentage of the total numbers undergoing a prostaglandin-induced abortion. Nevertheless, the incidence of unplanned subsequent pregnancies in the index group $\left(65^{\circ}{ }_{11}\right)$ is disturbingly high compared with the control group $\left(36^{\circ}{ }^{\prime}\right)$. We analysed these patients' details, and found that unmarried teenage patients of the lower social class are at special risk. Further, there was a larger proportion of therapeutic abortions in the second trimester in the index group than the control group, suggesting that the previous induction of abortion with prostaglandin-probably more unpleasant than a surgical aspiration under anaesthetic-is no deterrent. Apparently the challenge of the conscientious use of effective contraception is still greater than the fear of a further therapeutic abortion.
We thank Ms Jean Fedrick and Mr M P Embrey for advice and criticism on the preparation of this paper; the consultant staff in Oxford for allowing us access to the notes of patients admitted under their care; and the medical practitioners. who so readily assisted with details of patients who were managed outside Oxford. Part of this work was supported by a grant from the World Health Organisation.

\section{References}

${ }^{1}$ Department of Health and Social Security, On the State of the Public Health for the year 1975, p 64. London, HMSO, 1976.

2 Registrar General's Statistical Review of England and Wales for 1973, supplement on Abortion, p 9. London, HMSO, 1974.

3 MacKenzie, I Z, Hillier, K, and Embrey, M P, British Medical fournal, $1974,4,683$

' Kajanoja, P, et al, Acta Obstetricia et Gynecologica Scandinavica, 1975, suppl $37,51$.

${ }^{5}$ MacKenzie, I Z, and Hillier, K, International fournal of Gynecology and Obstetrics, 1975, 13, 209.

${ }^{6}$ Embrey, M P, British Medical fournal, 1970, 2, 258

'Embrey, M P, Hillier, K, and Mahendran, P, Advances in Biosciences, 1973, 9, 507

${ }^{8}$ MacKenzie, I Z, Embrey, M P, and Hillier, K, fournal of Obstetrics and Gynaecology of the British Commonwealth, 1974, 81, 554.

${ }^{9}$ MacKenzie, I Z, and Embrey, M P, British fournal of Obstetrics and Gynaecology, 1976, 83, 505.

10 Daling, J R, and Emanuel, I, Lancet, 1975, 2, 170.

1 Wright, C S W, Campbell, S, and Beazley, J, Lancet, 1972, 1, 1278.

${ }^{12}$ Richardson, J A, and Dixon, G, British Medical fournal, 1976, 1, 1303.

${ }_{13}$ Trussell, J, British fournal of Hospital Medicine, 1973, 9, 601.

${ }^{14}$ Butler, N R, and Bonham, D G, Perinatal Mortality, p 14. London, Livingstone, 1973.

${ }_{15}$ Vessey, M P, and Doll, R, Proceedings of the Royal Society. Series B. Biological Sciences, 1976, 195, 69.

16 Panayoti, P P, et al, American fournal of Obstetrics and Gynecology, 1972, 114, 507.

1: Johnstone, F D, et al, British Medical fournal, 1976, 1, 68.

${ }_{18}$ Murray, J, Medical fournal of Australia, 1974, 2, 717.

19 Kajanoja, P, et al, Fournal of Obstetrics and Gynaecology of the British Commonwealth, 1974, 81, 242.

20 MacKenzie, I Z, and Hillier, K, British Medical fournal, 1974, 4, 405.

${ }^{21}$ MacKenzie, I Z, British Fournal of Obstetrics and Gynaecology, 1976, 83, 780 .

(Accepted 24 August 1977)

\title{
Should the indications for prenatal chromosome analysis be changed?
}

\author{
JOHN PHILIP, JENS BANG, METTE MADSEN
}

British Medical fournal, 1977, 2, 1117-1119

\section{Summary}

Amniocentesis for chromosome analysis was performed in 1086 pregnant women, 739 of whom had an increased risk of giving birth to a child with chromosome abnormalities. Such abnormalities were found in almost iden-

\footnotetext{
Department of Obstetrics and Gynaecology YA, Righospitalet, University of Copenhagen, Copenhagen

JOHN PHILIP, MD, professor of gynaecology

Department of Obstetrics, St Joseph's Hospital, Copenhagen JENS BANG, MD, head of department

tical proportions among the fetuses with an increased risk $(1.2 \%)$ and among those with no increased risk $(1.4 \%)$. Findings in several other studies seem to confirm that there is no significant difference between the risk groups in the proportion of abnormalities found.

This suggests that our current risk groups may not be the right ones, but a much larger study is needed to confirm this.

\section{Introduction}

Prenatal chromosome analysis is now considered to be part of routine prenatal care in many obstetric departments. Investigation is usually offered to women with a known increased risk of having a child with a chromosome abnormality. The child is recognised to be at risk when $(a)$ one of the parents has a balanced translocation or is a mosaic; (b) the mother is over 35 (or 40) years; or (c) the mother has given birth to a child with a chromosome abnormality. Furthermore, families with serious X-linked 
diseases may wish to selectively abort male fetuses. Several studies of the incidence of chromosome abnormalities in high risk cases have been carried out. ${ }^{1-3}$

In women without an increased risk of carrying a fetus with a chromosomal abnormality, chromosome analysis is relatively rarely carried out. In reviewing our own series of 1086 cases we found an unexpectedly high proportion of women with a low risk giving birth to children with chromosome abnormalities. This suggested that the risk groups used today may not be the right ones. But our figures are small and larger series are necessary. We describe here our results in the hope that other centres will include "low" risk mothers among those undergoing chromosome analysis.

\section{Subjects and methods}

The series consisted of 1086 women who had consecutive fetal chromosome analyses in our unit. The unit accepts high-risk cases as well as normal women from a large area. Though the catchment area is ill defined, we cannot identify any bias in the type of referrals.

On referral all women who had an increased risk of having a chromosomally abnormal baby were offered amniocentesis (fewer than 10 did not accept the offer). Furthermore, amniocentesis was offered to women whose infants were at risk of either other detectable genetic diseases, such as inborn errors of metabolism, or anencephaly or spina bifida. In all these cases chromosome analysis was also carried out. Several women underwent amniocentesis for other reasons; they included those who specifically asked for amniocentesis but did not have an increased risk of having a chromosomally abnormal fetus.

Amniocentesis and culture of fetal cells were carried out according to earlier published methods. ${ }^{45}$

\section{Results}

The series was divided into two groups: women with an increased risk of having children with chromosomal disease, and women with no such high risk.

Table I shows the results of fetal chromosome investigation in the high-risk group. Of the 739 fetuses, nine $(1.2 \%)$ had a chromosome abnormality. Furthermore, nine male fetuses were found in families with an X-linked disease. Chromosome analysis was also performed in 347 fetuses in the low risk group: five $(1.4 \%)$ abnormalities were found (table II). The numerical risk of having a fetus with a chromosome abnormality was thus identical in both groups $(\mathbf{P}>0.99)$. The total number of balanced translocations was seven, three of which occurred in families without previously known familial translocation.

TABLE I-Results of studies of fetal chromosomes in mothers with an increased risk of having chromosomally abnormal fetuses

\begin{tabular}{|c|c|c|}
\hline Indication for amniocentesis: & $\underset{\text { investigated }}{\text { No }}$ & $\begin{array}{l}\text { No (",) with } \\
\text { abnormalities }\end{array}$ \\
\hline 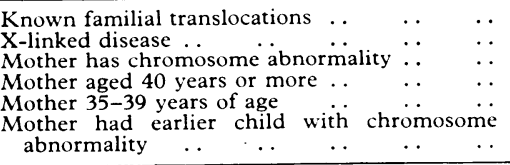 & $\begin{array}{r}4 \\
20 \\
3 \\
243 \\
422 \\
47\end{array}$ & $\begin{array}{l}1^{*}(25) \\
(9 \text { males }(45)) \\
0 \\
7+(2 \cdot 9) \\
1_{+}^{+}(0 \cdot 2) \\
0_{+}^{+}\end{array}$ \\
\hline $\begin{array}{ll}. & \end{array}$ & 739 & $\begin{array}{c}9(1 \cdot 3 ; 2.5 " \text { "if } \\
9 \text { males are } \\
\text { included })\end{array}$ \\
\hline
\end{tabular}

* Three further fetuses were carrying the familial translocation in bolanced form. †Plus two balanced translocations.

†Plus one balanced translocation.

Table III lists the chromosome abnormalities. The balanced translocations are not included. The chromosome abnormalities that caused severe malformations-that is, the autosomal trisomies-were all found in the group with an increased risk. As the numbers were small, the distribution of abnormalities (sex chromosome abnormalities: autosomal abnormalities) may have been due to chance. The abnormal fetuses in the group with no known increased risk all had sex chromosome abnormalities. Assuming that the risk of severe
TABLE II-Results of studies of fetal chromosomes in mothers with low risk of having chromosomally abnormal fetuses

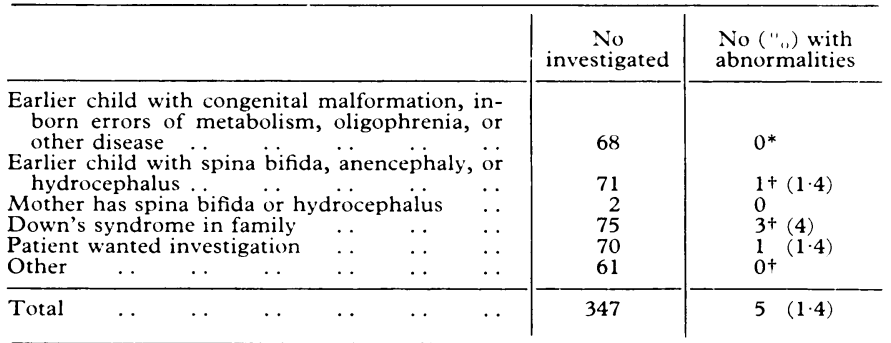

* One case of congenital adrenal hyperplasia. +Plus two cases of raised $\alpha$-fetoprotein levels, indicating anencephaly. +Including one case of a 46, XX male discovered after delivery. \$One case of balanced translocation.

TABLE III-Chromosomal abnormalities present (excluding balanced translocations)

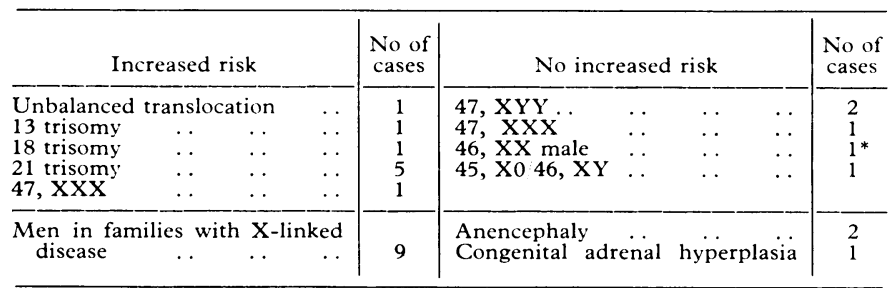

*Diagnosed after delivery.

(autosomal) abnormalities was the same in the two groups the probability of these findings occurring by chance was $3.7 \%$.

\section{Discussion}

The average frequency of chromosome abnormalities in liveborn babies is about $0.5^{\circ}{ }_{1},{ }^{6} \mathrm{~A}$ review of several published reports showed 2601 fetuses who had been investigated for chromosome abnormalities although they did not have an increased risk of such abnormalities. About 1" $1^{\text {" had abnormal }}$ chromosomes (table IV).

The frequency of chromosomal abnormalities in our two groups of fetuses was significantly different from the $0.5^{\prime \prime}{ }_{\text {, found }}$ in live-born babies $(P=0.012$ and $P=0.036$ respectively). But it should be remembered that other workers have found higher than expected frequencies of abnormalities in prenatal series.

The lack of any significant difference in the incidence of chromosome abnormalities in fetuses from high-risk and lowrisk groups and the significant difference between fetal and neonatal findings may have been due to chance because of small numbers and sampling errors. One possible explanation may be that the so-called non-risk groups in fact included several patients with risk factors. The three pairs of parents of the chromosomally abnormal children in one low-risk group (Down's syndrome in family) all had normal chromosomes, except for one mother who had an unknown balanced translocation affecting chromosomes 6 and 8 . Furthermore, all the mothers with chromosomally abnormal children in the low-risk group were aged under 30 years. Inclusion of high-risk cases in the low-risk group therefore probably did not bias the results.

There were fewer abnormal cases in our high-risk group than in other series (see table IV) and in series of newborn infants. Abnormality rates in the second trimester are known to be higher than in the newborn because of losses by spontaneous abortions and stillbirth. But there is no clear explanation of the low figures in our patients. We did not lose cases because of late amniocentesis, as most amniocenteses were performed in the 14 th or 15 th week, and less than a quarter were done after the 16 th week. The spontaneous abortion rate in our first 550 cases 
TABLE IV-Survey of selected series with large numbers of cases to assess incidence of chromosomal abnormalities in fetuses with and without an increased risk of abnormality

\begin{tabular}{|c|c|c|c|c|c|c|c|c|c|c|c|}
\hline & & & & & & & & \multicolumn{2}{|c|}{$\begin{array}{l}\text { Without increased risk } \\
\text { of chromosome abnormalities }\end{array}$} & \multicolumn{2}{|c|}{$\begin{array}{l}\text { With increased risk } \\
\text { of chromosome abnormalities }\end{array}$} \\
\hline 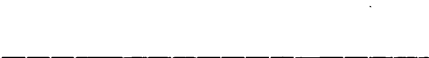 & & & & & & & & $\begin{array}{c}\text { No of } \\
\text { pregnancies }\end{array}$ & $\begin{array}{c}\text { No ("..) of } \\
\text { abnormalities }\end{array}$ & $\begin{array}{c}\text { No of } \\
\text { pregnancies }\end{array}$ & $\begin{array}{c}\text { No (") of } \\
\text { abnormalities }\end{array}$ \\
\hline $\begin{array}{l}\text { European Collaborative Study }{ }^{3} \\
\text { Canadian Medical Research Council } \\
\text { German Medical Research Council: } \\
\text { German } \\
\text { Ferguson-Smith and Ferguson-Smith } \\
\text { Present series }\end{array}$ & $\begin{array}{l}\cdots \\
\cdots \\
\cdots \\
\cdots\end{array}$ & $\begin{array}{l}\cdots \\
\cdots \\
\cdots \\
\cdots\end{array}$ & $\begin{array}{l}\cdots \\
\therefore \\
\therefore \\
\cdots\end{array}$ & $\begin{array}{l}\cdots \\
\therefore \\
\cdots \\
\cdots\end{array}$ & $\begin{array}{l}\cdots \\
\therefore \\
\cdots \\
\cdots\end{array}$ & $\begin{array}{l}\cdots \\
\cdots \\
\cdots\end{array}$ & $\begin{array}{l}\cdots \\
\therefore \\
\therefore \\
\cdots\end{array}$ & $\begin{array}{l}711 \\
191 \\
843 \\
497 \\
359\end{array}$ & $\begin{array}{c}12(1 \cdot 7) \\
2(1 \cdot 1) \\
3(+?)(0 \cdot 4) \\
3(0 \cdot 6) \\
5(1 \cdot 4)\end{array}$ & $\begin{array}{r}4788 \\
829 \\
2547 \\
433 \\
739\end{array}$ & $\begin{array}{r}135(2 \cdot 8) \\
21(2 \cdot 5) \\
68(2 \cdot 6) \\
12(2 \cdot 7) \\
9(1 \cdot 3)\end{array}$ \\
\hline Total & . & $\ldots$ & . & $\ldots$ & $\ldots$ & . & $\ldots$ & 2601 & $25(0.96)$ & 9336 & $245(2 \cdot 6)$ \\
\hline
\end{tabular}

was $2 \cdot 1^{\circ}{ }_{0}$, which corresponded to the spontaneous abortion rate in women not having amniocentesis.

We are therefore left with the fact that we found the same proportion of abnormalities in a group of fetuses with a low risk as in a group with a high risk. These findings raise several questions. Firstly, is it justified to screen all pregnant women, considering that a high proportion of the fetal abnormalities found will not be severe ? Secondly, is it justified not to screen the whole population of fetuses, considering that there is a and that amniocentesis is a fairly safe procedure ${ }^{*}$ Thirdly, is $1^{\circ}{ }_{\text {, }}$ risk of chromosomal abnormalities in fetuses with a low risk it justified to abort fetuses with chromosome abnormalities that do not cause very severe congenital malformations or mental retardation?

Our present definition of risk groups may not be correct. But larger series must be investigated, and further discussion and explanation of the problems are needed before decisions are made to enlarge the prophylactic programmes for preventing chromosomal diseases.
This paper was supported in part by the Danish Medical Research Council.

\section{References}

${ }^{1}$ Canadian Collaborative Study, Canadian Medical Research Council Report No 5. Ottawa, CMRC, 1977.

2 Deutschen Forschungsgemeinschaft, Informationsblatt No 10. München, Deutschen Forschungsgemeinschaft, 1976.

${ }^{3}$ Galjard, H, Cytogenetics and Cell Genetics 1976, 16, 453.

4 Bang, J, and Northeved, A, American fournal of Obstetrics and Gynecology, 1972, 114, 599.

${ }^{5}$ Philip, J, et al, Acta Obstetrica et Gynecologica Scandinavica Supplementum, 1974, 29, 1 .

6 Jacobs, P A, et al, Annual of Immunological Genetics, 1974, 37, 359.

- Ferguson-Smith, M A, and Ferguson-Smith, M E, in Prenatal Diagnosis Colloquium, ed E Bouvé, p 81. Paris, INSERM, 1976.

${ }^{8}$ NICHD National Registry of Amniocentesis Study Group, fournal of the American Medical Association, 1976, 236, 1471.

(Accepted 24 August 1977)

\title{
Primary excision of brain abscess
}

\author{
ABDUR R CHOUDHURY, JULIEN C TAYLOR, ROGER WHITAKER
}

British Medical fournal, 1977, 2, 1119-1121

\section{Summary}

Sixteen consecutive patients with brain abscess, including two with multilocular and two with infratentorial abscesses, were treated by primary total excision of the abscess. The patients were followed for six months to three years. Only one patient died and there were no recurrences.

Immediate primary excision is therefore the treatment of choice in brain abscess.

\section{Introduction}

In 1928 Sargent $^{1}$ was the first to advocate total extirpation of brain abscesses without drainage. In 1946 Sachs $^{2}$ reviewed a series of 142 cases of brain abscess and concluded that "excision without drainage is the ideal procedure." Then and later total excision has been recommended by several workers, ${ }^{3-8}$ and

\footnotetext{
Regional Departments of Neurosurgery and Neuroradiology, Derbyshire Royal Infirmary, Derby DE1 $2 Q Y$
DQ

ABDUR R CHOUDHURY, FRCS, neurosurgical registrar

JULIEN C TAYLOR, FRCS, consultant neurosurgeon

ROGER WHITAKER, FRCR, consultant neuroradiologist
}

the feasibility of primary surgical removal, with an attendant reduction in both mortality and morbidity, has been clearly shown. ${ }^{5-10}$ It is now clear that the mortality of brain abscess relates to its space-occupying effect, ${ }^{6}{ }^{811}$ which is caused by both the lesion and its surrounding brain oedema. The extent of the oedema is often disproportionate to the size of the abscess and oedema may be great when the abscess is small. This, we believe, explains the inadequacy of aspiration in preventing death from acute compression of the brain stem. Furthermore, repeated aspiration often does not bring about improvement before excision, especially with an acute lesion, and aspiration or drainage may miss some loculi in multilocular abscesses. Many patients treated by aspiration will improve clinically, although the abscess continues to expand. ${ }^{12}$ Because the oedema is partly inflammatory, a direct and more radical approach is necessary, not only to avert immediate disaster but also as the most effective way of eliminating recurrences.

Although primary excision of brain abscess has been shown to be an improvement over other methods, it does not yet enjoy wide acceptance, and hence this communication reports our favourable experiences of primary excision of brain abscesses in 16 consecutive patients.

\section{Patients and methods}

Since the implementation of primary excision of brain abscess by the senior author (JCT) in this unit, 16 patients, including two with 